\title{
O papel da língua no fortalecimento da identidade étnica dos Xukuru da Serra de Ororubá em Pesqueira-PE
}

The role of language in strengthening ethnic identity of the Xukuru from Serra de Ororubá in Pesqueira-PE

El papel de la lingua en fortención de la identidad etnica de los Xukuru de la Sierra de Ororubá en Pesqueira-PE

Solange Carvalho ${ }^{1}$

\section{Resumo}

CARVALHO, Solange. O papel da língua no fortalecimento da identidade étnica dos Xukuru da Serra de Ororubá em Pesqueira-PE. Rev. CઐTrópico, v. 43, n. 2, p. 125-146, 2019. DOI: https:// doi.org/10.33148/Cetropicov43n2(2019)art.6

Parte de um estudo maior, realizado em nossa Tese de Doutorado, defendida em 2018, no Programa de Pós-Graduação em Letras, UFPE, este artigo trata da questão da língua no processo de fortalecimento da etnicidade dos Xukuru da Serra de Ororubá, residentes em Pesqueira-PE, trazendo como foco as consequências do apagamento linguístico. No entendimento de que a língua é o principal elemento de uma cultura, mas não o único, e que eles perderam a língua ancestral, mas exigem o reconhecimento de sua identidade étnica em respeito a seus rituais sagrados. Nosso objetivo é demonstrar o fortalecimento de sua etnicidade a partir de outros elementos de igual importância cultural além da língua. A perda da língua para os Xukuru é alvo de suspeição e preconceito quanto a sua identidade étnica. Os resultados das discussões apontam para historiografia de lutas, mas também de perdas e danos em uma tentativa ainda atual de invisibilização dos povos indígenas pela política da integralidade que, ao considerá-los brasileiros, corroboram o enfraquecimento de sua etnicidade.

Palavras-chave: Apagamento linguístico. Processo de dominação. Diversidade linguística.

Doutora em Linguística pela Universidade Federal de Pernambuco (UFPE). Professora de Sociolinguística na Faculdade Luso-Brasileira. Revisora linguística na Fundação Joaquim Nabuco (Fundaj). Email: carvalho.soalnge@gmail.com. Orcid: https://orcid.org/0000-0002-9621-0154. 


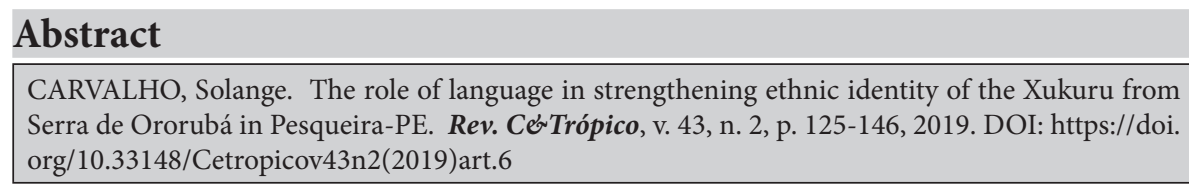

Part of a larger study conducted in our Doctoral Thesis, defende in 2018, in the Graduate Program in Letters, UFPE, this article addressed the language issue in the process of strengthening the ethnicidy of the Xukuru of Serra de Ororubá residents of Pesqueira-PE, focusing on the consequences of language erasure. Underestandin that language is the man element of a cultura, but not the only one, and that they have lost heir ancestral language, but demand recognition of their ethinic identity in respect of their sacred rituals. Our goal is to demonstrate the strengthening of its ethnicity from olher elements of equal cultural importance hesides language. The loss of language to de Xukuru is a tardet of suspicion and prejudice regarding their ethnic identity. The results of the discussions point to the historiography of struggles, but also of loss and demage in a still current attempt to make indigenous peoples invisible through the politics of integrality that considering them Brasilian, corroborate the wekening of their ethnicity.

Keywords: Linguistic erasure. Process of domination. Linguistic diversity.

\section{Resumen}

CARVALHO, Solange. El papel de la lingua en el fortalecimiento de la identidad etnica De los xukuru de la sierra de ororubá en Pesqueira-PE. Rev. CઐTrópico, v. 43, n. 2, p. 125-146, 2019. DOI: https://doi.org/10.33148/Cetropicov43n2(2019)art.6

Parte de un estudio más amplio, realizado en nuestra Tesis Doctoral, defendida en 2018, en el Programa de Posgrado en Letras, UFPE, este artículo aborda El problema del idioma en el proceso de fortalecimiento de La etnia Del Xukuru de la Sierra de Ororubá, residentes de Pesqueira-PE, centrándose en las consecuencias de La eliminación Del lenguaje. Comprender que El idioma es El elemento principal de una cultura, pero no El único, y que han perdido su idioma ancestral, pero requieren el reconocimiento de su identidad étnica en respeto a sus rituales sagrados. Nuestro objetivo es demostrar el fortalecimiento de su origen étnico a partir de otros elementos de igual importancia cultural además de su idioma. La pérdida de lenguaje para los Xukuru es sospechoso y prejuicioso con respecto a su identidad étnica. Los resultados de las discusiones apuntan a La historiografia de las luchas, pero también de La pérdida y del daño en un intento, todavía actual, de hacer invisibles a los pueblos indígenas por la politica de integralidade que, considerándolos brasileños, corrobora El debilitamiento de su origen étnico.

Palabras clave: Borrado linguístico. Proceso de dominación. Diversidade linguística. 


\section{Introdução}

Este artigo é fruto de nossa tese de doutorado intitulada "A língua e o fortalecimento da identidade étnica dos Xukuru da Serra de Ororubá em busca do sentido do Ser". Trata-se de um grupo indígena, de Pesqueira-PE, que vivencia um processo de fortalecimento de sua etnicidade, ressentindo-se do apagamento da língua ancestral. O referido estudo envolveu o entrelaçamento de distintas áreas do saber (Linguística, Antropologia, Filosofia), a fim de melhor compreender o seu objeto de estudo.

No entendimento de que a língua é um dos principais instrumentos utilizados no processo de dominação de um povo, construímos este artigo com o fim precípuo de discutir o fortalecimento da identidade étnica dos Xukuru a partir de elementos de sua cultura, como apresentado nos resultados da pesquisa realizada entre os Xukuru com enfoque no apagamento linguístico e suas consequências. Os Xukuru se destacam entre os demais povos indígenas do Nordeste por sua organização e forma de enfrentamento junto às instâncias de poder nas reivindicações por seus direitos. Ratificar essa luta se configura mais um retorno social a esses guerreiros resistentes que tão bem nos acolheram em nossas incursões.

Esta pesquisa é analítica de abordagem qualitativa, apoiada nos autores de referência nas questões da língua, sobretudo das línguas indígenas, a exemplo de Ayron Rodrigues (1976), Oliveira (1998; 2011), Lapenda (1962) e na analítica existencial de Heidegger (2005; 2015; 2015b; 2015c) quanto ao Ser, não o ser étnico, autoidentificado, mas o Ser o habita. Ao longo da revisão literária, fizemos uso de intertextualização como recurso da língua e utilizamos Literatura de Cordel como recurso de estilização para reforçar a voz analítica condutora da temática, com o intuito de tornar a conferir leveza à leitura dos fatos.

Estruturamos as reflexões em três seções. Em primeira instância apresentaremos a importância da língua no processo de dominação. Posteriormente discorremos sobre as consequências do apagamento linguístico que impactou diretamente os grupos indígenas do Nordeste, enfocando o caso dos Xukuru. Por fim, discutimos a busca pela revitalização da língua ancestral pelo viés filosófico da analítica heideggeriana e pelo linguístico.

\section{A língua e o processo de dominação}

O processo de dominação portuguesa nas terras posteriormente chamadas brasileiras data do século XVI, no período Colonial, quando fora colocado em prática, como estratégia de aproximação, o projeto de conhecer a língua da gente que primeiramente habitava a Costa do chamado Novo Mundo.

Como dominar um povo sem conhecimento de sua cultura, sobretudo, de sua língua? A língua é um dos principais elementos de uma cultura e é por meio da imposição da língua do dominador que se consegue subjugar os povos indígenas. Ao perder a língua, perdem-se as práticas culturais. Possivelmente essa fora a motivação do Marquês de Pombal. 
[...] não é somente a necessidade de promover o afeto e veneração ao Príncipe, que insiste na erradicação de uma língua e sua substituição pela língua do Príncipe, há também o reconhecimento implícito da forte associação entre língua e cultura e a crença que sem a língua considerada bárbara, os costumes, ou seja, as práticas culturais associadas a tal língua seriam também erradicadas (HOFFNAGEL, 2005, p. 225-226).

Como explícito pela referida antropóloga, a língua e a cultura têm uma relação de imbricação, portanto, com a substituição da língua materna pela língua da Coroa, podemos afirmar que os povos indígenas sofreram uma violência simbólica quando tiveram que absorver a cultura alheia durante o aprendizado dessa língua estrangeira, como bem explicitamos na Tese:

Com o auxílio da Igreja e seu projeto de expansão da fé, usa a língua como principal ferramenta missionária para buscar conversões pela alfabetização, uma vez que as cartilhas portuguesas disseminadas nas civilizações que pretendiam alcançar não somente na América e em África, eram repletas de textos religiosos, ou seja, os povos dominados aprendiam a ler, podemos inferir, no contato com a fé alheia (CARVALHO, 2018, p. 42).

Assim, quando afirmamos que os povos indígenas aprenderam a ler com a fé alheia, ratificamos que a língua desempenha um papel essencial no processo de dominação, porque de posse da língua pode-se compreender a cultura de um povo e ao impor sua cultura, o invasor português pôde manipular outro elemento de suma importância na cultura: a fé. Ao apresentar aos povos indígenas sua religião, trouxe-lhes a noção de bem e mal, de pecado, sentimentos esses desconhecidos dos povos originários.

Ao intentarem avançar para o interior do país tal imposição linguística, no entanto, os invasores portugueses encontram a resistência dos Tapuias aos quais chamaram "povos de língua travada". Esses resistentes não quiseram aprender o idioma possivelmente por rejeitar a dominação e resistindo é natural que o tenham feito, rejeitando com violência aos investidores holandeses e aos portugueses.

[...] No caminho se defrontaram com a resistência daqueles povos que chamavam de índios bravios, os não submetidos, e os enfrentaram com tropas formadas pelos próprios agregados e dependentes. Quando, porém, essa resistência começou a se fazer mais ferrenha e organizada, a iniciativa militar dos colonos não foi suficiente, e o medo de serem varridos do sertão levou-os a recorrer à Coroa que, por sua vez, empreendeu uma investida maciça para conquistar definitivamente a região (SILVA, 2010, p. 136). 
Diante dessa resistência a solução que favorecia aos invasores portugueses foi o estabelecimento de três estratégias: guerra, conversão e mistura.

A primeira estratégia, chamada guerra justa, se concretiza nas entradas dos bandeirantes no Sertão, cujo principal argumento era o enfrentamento da hostilidade indígena, ou seja, por não se submeterem à exploração de suas terras eram chamados de selvagens, brutos e hostis. Tais conflitos se alongaram por dois séculos, nestes estados: Rio Grande do Norte, Paraíba, Ceará e Pernambuco. Como consequências dos prolongamentos desses conflitos, ocorre um denso povoamento no interior das extensas sesmarias e o "amansamento" dos índios.

Paralelamente a essa estratégia de guerra declarada e justificada, ocorre a segunda estratégia: conversão. Os missionários jesuítas, capuchinos, oratorianos e franciscanos repartiram entre si os aldeamentos, mas tinham acabado com escravidão para os índios, o que suscitou sua retirada do poder dos missionários sobre os aldeamentos em 1775.

Desde 1759, quando o marquês de Pombal havia expulsado os jesuítas, nenhum projeto ou voz dissonante se interpunha no debate quando os missionários são reintroduzidos no Brasil, na década de 1840, ficaram estritamente a serviço do Estado. Os grupos indígenas, sem representação real em nível algum, só se manifestam por hostilidades, rebeliões e eventuais petições ao imperador ou processos na Justiça (CUNHA, 1992, p.133).

A última estratégia que corroborou para o deslocamento dos povos indígenas de sua cultura primeira fora a mistura, conforme registra Arruti (1995). O casamento entre os indígenas e os portugueses, pela organização administrativa da Colônia, foi o grande incentivo para assimilação (física e cultural), utilizado com o propósito de descaracterizar e fazer vigorar o discurso do apagamento ou mesmo da extinção dos povos originários e, com isso, justificar a posse de suas terras.

Para ratificar as estratégias de dominação, recorremos a um recurso estilístico da língua, trazendo um trecho de nosso cordel sobre os Xukuru em que fazemos menção de tais estratégias.

$$
\begin{aligned}
& \text { No marco da independência } \\
& \text { Registrou-se a permanência } \\
& \text { Do amado imperador } \\
& \text { Diga o povo que fico! } \\
& \text { Bradou o jovem senhor. } \\
& \text { Esse brado teve efeito } \\
& \text { Mas não foi daquele jeito } \\
& \text { que a liberdade chegou } \\
& \text { Fizeram amansamento. } \\
& \text { Registro muito tormento } \\
& \text { Conversão e casamento } \\
& \text { Pra chegar onde chegou. }
\end{aligned}
$$


Nasce o indigenismo ou Serviço de Proteção aos Indígenas (SPI) em que os povos originários seriam utilizados como mão de obra nacional.

Diante disso, consideramos pertinente discorrer sobre a etnologia indígena do Nordeste que vem suscitando interrogações desde o repentino crescimento dessas etnias, ou pelo menos o seu registro. Dez etnias nos anos 1950 passaram a 23 etnias, em 1994, segundo Oliveira (1998), o qual explicita como se deu essa etnologia, ou seja, com que intensidade esses índios passaram a ser objeto de investigação nos cânones científicos e sugere que essas primeiras investigações sinalizam seu apagamento pela "mestiçagem".

O Nordeste foi uma região do Brasil que sofreu visível impacto da redução da população indígena, mas também a que mais reivindicou o reconhecimento estatal de sua identidade étnica. Segundo registra o IBGE (2010), após o doloroso processo de autoidentificação por que tiveram que passar para comprovação de sua etnicidade, houve um crescimento significativo da população indígena no Nordeste. Etnogênese ${ }^{2}$ foi o termo usado para referirem-se a esses povos, porém não aceito por muitos estudiosos, a exemplo de Oliveira (1998), por remeter à "reinvenção" de etnias já reconhecidas. Podemos chamá-los de resistentes, pois foi essa resistência que os conduziu ao movimento das Retomadas e conquista dos aldeamentos. Corroborando Arruti (1995), segundo o qual o Nordeste é a mais antiga região de colonização e onde a expropriação indígena de todos os aldeamentos ocorrera oficialmente em menos de dez anos (1860-1870)3. Além do mais, também foi no Nordeste onde se destacaram intensas reivindicações por reconhecimento de etnicidade indígena.

Os Xukuru, cabe registrar, destacam-se entre os demais povos indígenas do Nordeste nas reivindicações pelo fortalecimento de sua etnicidade e pelos aspectos culturais de sua tradição Cultural. Representados por Xicão, lideraram o movimento das Retomadas, iniciado em $1998 .^{4}$

Nos dias atuais, os povos indígenas têm mais do que se orgulhar de sua identidade étnica e de sua ancestralidade. Talvez por isso, faça algum sentido chamar de etnogênese esse fenômeno de reconhecimento. Após séculos de repressão, em que precisavam negar a identidade para não serem perseguidos, hoje eles não somente se expõem como também, exigem reconhecimento de sua etnicidade, e seus direitos. O preconceito e a discriminação que foram motivos de constrangimento, hoje justificam suas lutas e suas reivindicações, por serem sujeitos de direito e assumirem ser o que de fato são.

Não há qualquer sentido hoje se falar em superioridade cultural o que já foi rechaçado desde Malinovisky (1978). Os indígenas do Nordeste foram invisibilizados pela educação formal como bem afirma Silva (2007), que passa uma imagem distorcida do índio.

Cabe chamar atenção para o termo etnogênese o qual remete aos "resistentes", grupos étnicos indígena do Nordeste cuja resistência os condiciona às chamadas "Retomadas" de sua cultura (território, história, saberes). Segundo registra Luciano (1998), trata-se de um fenômeno em que um povo reassume sua etnicidade, reafirmando-a, destacando os aspectos relevantes da cultura tradicional de sua etnia.

3 O autor se reporta ao caráter classificatório e jurídico da extinção oficial da desapropriação, alegando o conhecimento técnico por meio do parecer emitido pelas Comissões de Medição e Demarcação das terras consideradas devolutas quando de seu cadastramento devido à exigência da Lei de Terras de 1850 .

4 Cf. Texto de Chico Ludemir. Disponível em: https://www.revistacontinente.com.br/secoes/extra/povo-xukuru--pe-no-chao-e-raizes-profundas. Acesso em: 9 out. 2019. 
Sobre o impacto da perda da língua no fortalecimento da identidade étnica dos povos indígenas, que discorreremos na próxima seção, resumimos algumas considerações nesse repasso do efeito avassalador da dominação.

Se uma língua guarda segredos de sua etnia não há porque corroborarmos a designação de "glotocídio" indígena, sem considerar a perda de parte dos segredos milenares desses povos. As línguas indígenas passaram por um processo avassalador de deslocamento e apagamento, e mesmo ao completo desaparecimento.

O Nordeste foi a região em que os povos indígenas foram as maiores vítimas desse processo, em que somente os Fulni-ô de Águas Belas, em Pernambuco, conseguiram manter a língua ${ }^{5}$ usando-a ao lado do Português como bilinguismo.

O IBGE (2010) registra 1.300 línguas indígenas faladas no Brasil em 1500 e hoje esse quantitativo foi reduzido a 274 , sendo somente 180 catalogadas pelos linguistas, entre 896.900 falantes indígenas espalhados por 5.565 municípios. A imagem de um Brasil monolíngue é fortalecida em todas as instituições nacionais, as quais contribuem para a invisibilidade das línguas indígenas e da diversidade linguística brasileira.

Etnias em situação de bilinguismo estão suscetíveis à perda da língua, como possivelmente ocorrera com os antigos Xukuru que não mantiveram a sua língua ancestral, restando dela apenas alguns registros. Qualquer língua do mundo passa por variação e mudança, processo natural devido à interação entre os membros de uma comunidade dialetal, ou comunidade de fala na perspectiva de Labov ([1972], 2008).

É comum, e fato, que os falantes acomodem seus dialetos quando em situação de contato pelo processo de convergência, como designa Giles e Couplan (1991). Foi o que possivelmente ocorrera no processo de deslocamento e apagamento das línguas indígenas, pela estratégia da acomodação dialetal (convergência). Essa trajetória de apagamento linguístico não ocorreu, como não ocorre, por preferência. Houve imposição do europeu. Por questão de sobrevivência, os povos indígenas tiveram que acomodar seus dialetos ao Português e, como a língua em desuso se apaga, foi assim que o Português fixou residência, como explicitado nesta intertextualidade bíblica (JOÃO 1: 1-14) para resumir o processo de dominação no Brasil pela língua. ${ }^{6}$

1. No princípio era o Tupi. E o Tupinambá (como era conhecida a língua litorânea da família guarani) estava com os nativos e era a língua como representação falada por esses nativos.

2. O Tupi era a língua falada no princípio.

3. Todas as coisas eram comunicadas por intermédio do Tupi-guarani que ganhara espaço ao lado do Português. Sem os Jesuítas nada do que foi feito se fez.

4. A vida estava na língua e a língua era "a luz".

5. "A luz resplandece nas trevas e as trevas não prevalece".

6. Houve um grupo de missionários chamados Jesuítas, enviados pela Coroa Portuguesa que ajudou os nativos a disseminar a língua da Costa.

\footnotetext{
5 Como uma das formas de registro, construíram um dicionário da língua.

6 Carvalho (2018, p. 154)
} 
7. Os Jesuítas vieram como intermediários da luz, a fim de todos virem a crer por meio deles, descaracterizando, por outro lado, a etnicidade dos nativos do chamado Novo Mundo.

8. Eles foram expulsos e depois disso fora proibida a interação com Tupi e a Língua Portuguesa fixou residência.

9. A luz que passara a "iluminar" os homens em sua interação era agora o Português.

10. O Português estava no mundo dos indígenas, o mundo dos indígenas foi reconstruído por intermédio de políticas homogeneizadoras. $\mathrm{O}$ mundo contemporâneo dos indígenas (o caso dos Xukuru), porém, não conhecera sua língua ancestral.

11. Os direitos eram seus, mas eles não os reconheciam e não sabiam reivindicá-los, até o surgimento de um líder (Xicão).

12. A todos, porém, quantos lutaram, deu-lhes o direito à retomada do que era seu (aldeamentos).

13. Os quais não nasceram do sangue por linhagem direta, nem eram descendentes por vontade do homem não índio que os "protegiam" (SPI), mas de Deus (ou de seus "encantados" como acreditam em sua fé).

14. E a língua se fez presente e habitou entre eles, cheia de variações e mudança e de lógica indígena, e vimos a sua afirmação e reconhecemos sua etnicidade como genuína expressão de seu Ser. ${ }^{7}$

Podemos assim, relacionar esse processo às relações interétnicas entre indígenas e portugueses para melhor entender a supremacia do Português, o que ocorre somente com a imposição, pois inicialmente a predominância era das línguas indígenas. Os nascidos da miscigenação aprendiam o Português na escola, mas a língua de comunicação era a nativa. Afinal, bebiam a língua nativa pelo leite materno, ou seja, era com as mães indígenas com quem passavam mais tempo.

Quando a Coroa Portuguesa passou a impor o Português como uso obrigatório (século XVIII), já se falava a Língua Geral (Tupi antigo) e outras línguas, formando a família Tupi-Guarani (RODRIGUES, 1986 ; SILVA, 2015), o que facilitou o processo de aquisição da Língua Portuguesa. Os motivos que contribuíram para fragilizar o uso das línguas indígenas foram os mais diversos.

Os próprios membros das comunidades indígenas passaram a desencorajar o uso de sua língua nativa para evitar o estigma, resultando no enfraquecimento pelo desuso. Configura-se um grande desafio a manutenção da língua nativa, no interior do lar haja vista a interferência da segunda língua (L2) no contexto extrafamiliar (as relações sociais) ser uma constante. Não havia como evitar, portanto, tal interferência no contexto familiar, pois o contato gera acomodação dialetal.

Com a língua interagimos, pois é instrumento de constituição de identidade. Por sua importância nessa questão identitária, quando ocorre o glotocídio ou perda, "é

\footnotetext{
Para melhor compreensão do Ser, ler Heidegger (2007).
} 
possível se pensar no apagamento da etnia" (CARVALHO, 1918, p. 144). A etnicidade, contudo, é uma questão individual de pertencimento, e, segundo Cristal (1987), de consciência de sua identidade étnica.

Para discorrer sobre Identidade, etnicidade, cidadania e sua importância diferenciada para os indígenas, cabe inicialmente salientar que a discussão sobre identidade entre os não indígenas difere em valor e sentido do entendimento entre os povos indígenas. Para esses últimos, não se concebe falar de identidade sem relacioná-la à etnia. Importa para eles a identidade étnica ou etnicidade. $\mathrm{O}$ mesmo se dá com a cidadania, que eles buscaram alcançar para melhor angariar direitos entre a sociedade majoritária, como veremos nas subseções a seguir.

Mesmo entre os não indígenas, há divergência conceptual no que respeita à concepção de identidade. Muitos são os estudiosos que tratam da questão (HALL, 2002; BAUMAN, 2001; entre tantos outros). Para Hall (2002), o melhor entendimento da questão da identidade relaciona-se à concepção de sujeito ao longo da história, quais sejam: o sujeito do Iluminismo; o sujeito sociológico e o sujeito pós-moderno.

O primeiro, o sujeito do Iluminismo, refere-se à concepção da pessoa humana como um indivíduo centrado, unificado, dotado das capacidades de razão, de consciência e de ação, cujo "centro" consiste em um núcleo interior, que emerge pela primeira vez quando o sujeito nasce. Essa concepção de identidade permanece por toda a vida.

Na segunda concepção de sujeito, a identidade do sujeito sociológico reflete a complexidade crescente do mundo moderno e a consciência de que o núcleo interior, a que se refere o sujeito unificado, não é de um sujeito autônomo, mas formado na relação com o outro que considera importante para si. Nessa concepção de sujeito, a primazia e da cultura dos mundos que se habita. Trata-se de uma concepção interativa em que a identidade é formada na interação entre o eu e a sociedade. Em palestra proferida no Congresso de Filologia, em 2014, no Rio de Janeiro, a professora de sociolinguística, em suas palavras a seguir, corrobora Stuart Hall quanto à identidade do sujeito sociológico:

O eu real é formado e modificado pelos mundos exteriores e suas identidades. Projetamos a nós mesmos nessas identidades culturais e ao mesmo tempo internalizamos seus significados e valores. A identidade liga o sujeito à estrutura, estabilizando o sujeito e os mundos culturais em que ele habita (CARVALHO, 2014, p. 5).

Segundo registra Vandenbergue (2010), há três mundos; o mundo real, das relações invisíveis, existentes no plano teórico, o mundo do hábitus, ou seja, do estado de consciência e disposições do comportamento e o mundo teórico. Para a ciência sociológica, com inspiração humanista da ação social, o sujeito é tomado como referência ontológica última e está imerso no sistema de relações entre os indivíduos no espaço social (VANDENBERGUE, 2010 p. 56). As relações entre esses três mundos formam o sistema teórico das relações construídas. Bourdieu, com sua teoria da prática - movimento estruturalista sob a forte influência de Marx, Sartre, Habermas, Giddens - concebe o mundo em constante construção e verificação. 
A terceira concepção de identidade, a do sujeito pós-moderno, é aquela em que o sujeito reúne em si várias identidades, ou seja, as identidades culturais, nas quais nos projetamos, tornam-se provisórias, variáveis e problemáticas. Assim, o homem pós-moderno não tem uma identidade fixa, essencial ou permanente, mas uma "celebração móvel” dos sistemas culturais circundantes. Essa concepção é definida historicamente e não biologicamente. Nesse entendimento, assumimos identidades diferentes em diferentes momentos.

Nessa perspectiva de Hall (2002), a concepção de identidade é inerente às diferentes posições de sujeito assumidas ao longo da história e construídas discursivamente. A identidade pode mudar conforme nossos posicionamentos discursivos. A origem social é identificada conforme as identidades que assumimos e, pelo habitus, conforme preconiza Bourdieu (2007), em A Distinção.

Para melhor compreender o Ser Xukuru, no entanto, há que se compreender sua identidade étnica (etnicidade) tanto de suas raízes quanto das interferências durante sua trajetória de ser aí no mundo para retomar Heidegger (2015a), segundo o qual a incompletude do ser se dá pelo conhecimento adquirido ao longo de sua experiência de vida.

\begin{abstract}
A língua, com suas marcas dialetais, revela a ideologia de uma comunidade de fala, cujos membros (...) compartilham traços dialetais que a diferenciam de outra. Possivelmente tais comportamentos linguísticos advêm da interferência de "forças históricas" que atuam na atitude linguística desses falantes. Essa atitude tem relação direta com a visão de mundo dos falantes nativos (CARVALHO, 2014, p.3).
\end{abstract}

Conforme as palavras da referida autora, toda comunidade de fala tem uma ideologia que transparece no comportamento linguístico de seus membros. Há de se considerar, portanto, que o comportamento dialetal, dos que convivem em um mesmo espaço social, é interpelado, como dizem os analistas do discurso, por traços outros de línguas em contato, cujas forças históricas interferem na atitude e visão de mundo dos sujeitos, ou seja, em sua constituição identitária, ampliando-lhe a formação como "ser aí no mundo".

No entendimento de que esse mundo da ocupação remete ao Dasein na facticidade da vida: "designação para o caráter ontológico do nosso ser aí próprio" (HEIDEGGER, 2013, p. 3), para compreender o Ser Xukuru, esse ser étnico que busca o fortalecimento de sua etnicidade, consideramos pertinente discorrer sobre as concepções de identidade de Stuart Hall (2002) e a noção bourdieusianas de Habitus.

Quanto à cidadania ${ }^{8}$, é comum compreender que é a razão de ser de uma sociedade a qual somente alcançamos por requisitos morais e étnicos, que permitem nossa

\footnotetext{
Cidadania é um conceito filosófico, mas também um conceito prático e quem vai direcionar essa pragmática é o aparelho estatal (CARVALHO, 2018, p. 77).
} 
convivência em sociedade. Essa convivência deve se pautar por um ordenamento jurídico e um sistema burocrático que ordenam todo o seu funcionamento o qual, por sua vez, é consagrado na figura do Estado, que determina, de certa forma, os rumos de uma nação.

No caso da cidadania indígena brasileira, ela não deve ser pensada numa visão etnocêntrica a privilegiar pessoas que partilham as mesmas crenças e têm os mesmos símbolos, porque, se assim o for, excluiremos os povos indígenas, pois eles não partilham de nossos valores morais e éticos, tampouco da mesma crença e, como qualquer outra cultura, preservam os seus símbolos. É preciso esclarecer que a cidadania brasileira é estendida a eles quando o Estado lhes confere o direito de ter dupla cidadania. No caso dos xukuru, que falam a Língua Portuguesa, e, mesmo assim, com sentidos específicos de sua cultura, ainda que partilham a mesma língua, eles constroem sentidos distintos. $\mathrm{O}$ fato de a própria organização social, política e jurídica ser distinta, justifica essa dupla cidadania.

Dizer que a cidadania está circunscrita à territorialização, também é uma concepção estreita de cidadania, pois a grande expansão de terra brasileira é povoada de várias etnias com suas respectivas línguas, crenças e modos de ser no mundo. $\mathrm{O}$ Estado é o poder central, mas é exatamente por isso que pode levar os povos indígenas à contradição, pois, repetindo a indagação que fizemos em nossa pesquisa de doutorado: como seriam cidadãos sem possuírem de fato as terras, como propriedade? Afinal, a noção indígena de terras é de propriedade coletiva.

O fenômeno do apagamento linguístico veio afetando os povos indígenas desde a situação colonial, quando a quantidade de etnias e consequentemente de línguas foi se perdendo no tempo, atingindo avassaladoramente os povos indígenas do Nordeste, a ponto de causar suspeição se eles existiram em algum tempo.

As lutas e conquistas dos povos indígenas marcaram a historiografia brasileira, contudo, é possível afirmar, com base nos aspectos pontuados até então, que o processo de dominação, com as consequências de suas estratégias, foi de perdas e danos para esses povos, em que pese sua resistência.

\section{Perdas e Danos: da diversidade ao apagamento linguístico}

O que ocorrera de fato para que uma imensa quantidade de povos, com suas respectivas línguas tenham simplesmente desaparecido? Já tratamos das estratégias de dominação e tentativa de etnocídio e de glotocídio pelos dominadores portugueses, passamos a refletir essas consequências nefastas de apagamento. Se entendemos que a língua é o fio condutor da comunicação étnica e interétnica, e que os povos indígenas tinham sido obrigados a interagir apenas com a língua do seu dominador, não é sem propósito inferir que a língua materna sofrera o impacto do desuso, pois defendemos que língua viva é uma língua em uso.

Para compreender tais consequências, ou seja, o processo para o apagamento, portanto, não devemos prescindir da realidade pluriétnica desde os tempos da chegada dos europeus, que, como afirma o estudioso, de línguas indígenas, Rodrigues (1976, 
p. 17): "não são um povo. São muitos povos, diferentes de nós e diferentes entre si". Quando refletimos hoje a realidade historiográfica da formação do povo brasileiro, devemos considerar a questão da diversidade linguística como realidade diatópica. Falar em unidade linguística em um país de dimensões continentais como o Brasil já é, no mínimo, incoerente quanto mais quando sabemos da existência de muitas etnias com suas respectivas línguas habitando ainda que autorizadamente esse chão.

Ademais, a língua está atrelada ao prestígio social, numa sociedade de pretendentes ao status da classe superior, conforme Bourdieu (2007) é pertinente analisar a relação entre o habitus e as trocas linguísticas na dissimetria existente entre a língua e a fala. ${ }^{9}$

Cabe refletir a língua como um dos principais elementos representativos de uma cultura no processo de análise do habitus, que distingue os agentes na luta de classes. Afinal, o uso autorizado da língua é mais familiar à classe dominante, a qual tem mais acesso aos instrumentos normativos e de cujo gosto e estilo de vida são alvos de pretensão das classes de menor prestígio social.

Como entendido até então, a língua é considerada um instrumento de poder e como tal, o agente social, ou seja, o falante/ouvinte se enquadra nas disposições do mercado linguístico, conforme sugere Bourdieu (2007). Por isso, há um ajuste das práticas linguísticas comuns às práticas consideradas legítimas, que são as das classes dominantes. Assim, dá-se relevo às condições sociais de produção da fala. Para o referido sociólogo francês, o habitus linguístico é um habitus de classe, ainda que não se faça essa estratificação hoje, cabe a analogia com a relação de dominância à época colonial. Esse paralelo se dá pelo fato de essa relação de poder persistir até os dias hodiernos.

A língua é, pois, um bem simbólico de grande relevância para a etnia, que luta para conservá-la, pois é um patrimônio uma vez que simboliza a identidade e a memória de um povo.

$\mathrm{O}$ apagamento e a perda da língua materna nos levam a inferir que há uma pressão da sociedade majoritária a afirmar sua identidade étnica, como aconteceu aos grupos indígenas do Nordeste.

A problematização da língua para o Xukuru se dá nesse contexto de perda e tentativa de revitalização, em que outros elementos simbólicos equivalem em potencial como situação de identificação étnica, pois entendemos que a relação língua-nação está presente nos objetos simbólicos e rituais. Os antepassados perderam a sua língua, e muitos dos remanescentes sequer nem conheceram sua língua ancestral, porém, valores e sentidos inerentes a sua cultura são elementos preservados e perpetuados na Língua Portuguesa que falam. Esses valores é que os diferenciam dos não indígenas.

A heterogeneidade é a realidade de qualquer língua cujo sistema de relações de força se encarrega da distinção.

\footnotetext{
A língua é objeto de estudo da Linguística, elevada ao status de ciência no início do século XX por Ferdinand Saussure e a fala foi largamente difundida por William Labov nos meados do século XX. Para ganhar o status de ciência, carecia de um método e o sociolinguista americano foi buscar na Sociologia, cujo foco de análise era os fatos sociais, o método de fazer pesquisa científica. A Sociolinguística, em busca dos fatos da língua, por empréstimo de Émile Durkheim, vai ao campo, coletar o vernáculo nas relações sociais.
} 
Nas sociedades, a produção escrita é mais valorizada que a produção oral. Para Bourdieu (2007), a escrita, e não a fala, pode garantir a permanência da língua. Já que se trata de uma luta de classes, a classe dominante detém a chamada norma culta, aproximada da língua padrão, considerada legítima, detendo com isso o poder.

Para esse sociólogo, o prestígio dos agentes está intrinsecamente relacionado ao reconhecimento de seu capital simbólico. Por isso, as trocas linguísticas, com a carga da imposição simbólica conferida pelos agentes sociais, têm seu peso a depender das condições de produção das dicções sociais que subjaz ao uso linguístico. $\mathrm{O}$ poder da palavra e da ordem relaciona-se a ordem das coisas, uma vez que o poder ilocucional depende da ordem estabelecida socialmente. O poder performático do ato de fala deve ser reconhecido socialmente para que seja válido, ou seja, autorizado. Agir socialmente no mundo é uma pretensão dos agentes, que o faz mediante as trocas linguísticas, seja para insultar ou não. É preciso que haja autorização para uma realização performática do ato de fala.

Neste entendimento de relação de força, prestígio e imposição de língua, não se pode falar dos povos indígenas, em mais de 500 anos de Brasil, sem falar em genocídio, glotocídio, etnocídio ou como afirma Leite (2009, p. 5), de “perdas e extermínios". Por outro lado, não podemos deixar de registrar sua história de resistência em busca de fortalecimento de sua identidade étnica.

A luta indígena, com suas disputas simbólicas, permanece ainda objeto de estudo dos pesquisadores da cultura contemporânea. Ficou entendido que a diversidade cultural é o espaço em que se travam as lutas sobre as diferenças. Esse quadro revela a carência de projetos políticos de apoio à cidadania diferenciada, que tratem os invisibilizados em sua diferença não como assimilados, integrados como questiono o tratamento dado por Darcy Ribeiro aos povos indígenas do Nordeste, em trecho de nosso cordel sobre os Xukuru:

\author{
Será assimilação \\ Ou desaparecimento? \\ Como será o fomento dos índios da Região? \\ Por desgaste, etnocídio? \\ Ou extermínio, genocídio? \\ O próprio indigenista \\ Demonstra contradição. \\ Ora diz: são integrados \\ Cada vez menos diferenciado \\ Da sua gente ancestral! \\ Ora afirma, apesar disso \\ São tudo identificado \\ Como povo organizado \\ Diz em hora terminal.
}


A tentativa de apagamento étnico dos povos indígenas do Nordeste é percebida ao longo da historiografia, mas foi ignorada pelos não índios como observa Oliveira (2011). É mais amigável da parte dos governantes tratar esses povos como brasileiros para que, com isso, seja mais viável sua invisibilidade. Finalizo com outra expressão do peito em outra parte do mesmo $\operatorname{Cordel}^{10}$ :

\author{
[...] Ninguém tem qualquer direito \\ De negar ao ser indígena \\ A sua etnicidade. \\ É um total desrespeito \\ Arracar-lhe de seu peio \\ O que tem como verdade. \\ Pois quem aqui nessas terras \\ Foi habitante primeiro \\ Não quer ser considerado \\ Apenas um brasileiro [...]
}

O Xukuru, portanto, requer e reivindica ser respeitado em sua condição étnica, talvez isso possa justificar o investimento pessoal e coletivo na busca pela revitalização da língua, que pode ser interpretado como a soma de mais elementos para reduzir o preconceito da suspeição de serem eles mesmos o que sabem que são.

\title{
4. Os Xukuru e a busca da Língua Ancestral: os olhares analí- ticos na perspectiva da analítica existencial heideggeriana e na perspectiva da Linguística
}

Iniciamos esta seção pela perspectiva da analítica existencial heideggeriana. Para fazer uma analogia entre a busca intermitente pela língua ancestral remetemos à emblemática assertiva heideggeriana: "A linguagem é a casa do ser", afirma Heidegger (2005, p.8), o que significa dizer que a busca intermitente pela língua ancestral, sinaliza para uma busca pelo ethos perdido. Estrangeiro em sua própria casa, é como se buscasse a si mesmo ou parte de si.

O fato de os Xukuru hoje desconhecerem sua língua ancestral é motivo de angústia, posto que representa uma lacuna do "ser aí no mundo", o que se torna latente em sua busca incessante pela recuperação da língua Xukuru.

Conforme postula Heidegger (2015a, p. 97) a respeito da linguagem, trata-se de um sentimento de pertença: "prevalece e carrega a referência do homem na sua duplicidade ser e ente", pois, esclarece em outro momento: "o homem é recomendado à medida que pertence, como o ser que é, a uma recomendação que o requer e o reivindica" (HEIDEGGER, 2015c, p. 99). Portanto, buscar a essência da linguagem é uma experiência que difere da praticada pela metafísica.

\footnotetext{
10 Nosso arquivo pessoal.
} 
É preciso entender o que seja o acontecimento do Ser. O Ser heideggeriano busca a verdade e a verdade lhe vem ao encontro. O acontecimento do Ser Xukuru é preenchido por tudo que, ao longo da vida, atraiu para si, ou seja, à verdade do Ser que nele habita. É preciso entender as escolhas. São nossas escolhas definidoras de onde estamos, ou seja, escolhas acertadas ou não (o tempo se encarrega de mostrar), elas nos trouxeram exatamente até onde estamos hoje. Quanto às escolhas dos Xukuru desde a situação colonial, não é o caso de julgamento, mas podemos refletir sobre essa questão, por entendermos que o processo de escolhas foi gradativo, pois a convivência amadureceu e, embora tardiamente, apresentou-se como uma experiência dolorosa.

A experiência da busca pela língua ancestral é como a busca pela verdade do ser, pois nessa inquietude, os Xukuru seguem seu projeto de vida, abertos ao que lhe vem ao encontro, e isso é fazer a experiência com a linguagem, como sugere Heidegger (2015b), deixar que nos atravesse, avassale e transforme.

Ao refletirmos sobre esse Ser-aí (Dasein), lançado no mundo da ocupação, como se expressa o analista existencial, leva-nos a considerar que eles são o que são e não o que supomos que sejam.

Para discutir o olhar analítico na perspectiva da Linguística, há que se recorrer à questão colonial. $\mathrm{O}$ processo de deslocamento da língua materna, desde a situação colonial, a que foram submetidos os primeiros habitantes dessas terras (posteriormente chamada Brasil), resultou nessa situação de perda da língua ancestral. Há que se considerar, na procura pela ancestralidade linguística, as questões da linguagem em que se pode ampliar o escopo da investigação dos vestígios, uma vez que a língua articulada é parte da linguagem, mas não o único elemento. Entende-se que a insistência na tentativa de recuperação do que se perdeu, é que a língua simbolicamente ainda permanece como fonte de desejo para o fortalecimento identitário. É possível que seja estrategicamente uma instituição com mais força e poder para o reconhecimento identitário.

A tentativa de revitalização da língua sempre envolve lutas, descolamento e morte. Devemos pensar em um escopo maior quando tratamos da identidade étnica. Os Xukuru são falantes do Português como primeira língua, mas os atributos não materiais, culturais, simbólicos, enfim o capital simbólico que os constitui envolve essa linguagem, e tem como função outros atributos culturais que os fazem ser o que são. Portanto, não é sem propósito afirmar, que a interação linguística com a língua oficial, que os mais antepassados assimilaram e adotaram e os descendentes conheceram, tem peculiaridades semânticas que em muito difere da interação entre os falantes não indígenas.

Nessa busca programática de revitalização da língua ancestral, havemos de considerar a pertinência de uso como instrumentação cotidiana de comunicação, e também como registro, pois fortalece o material existente sobre os vestígios da Língua Xukuru. Há os registros de Lapenda (1962), em meados do século passado e, mais no final do século, o glossário do Mãe Natureza (ALMEIDA, 1997), ambos disponsibilizados em nossa Tese "A Língua e o fortalecimento da identidade étnica dos Xukuru da Serra do Ororubá em busca do sentido do Ser. ${ }^{11}$.

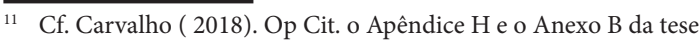


Sabemos que o tempo desgasta e transforma palavras e sentido, por isso dizemos que o léxico de uma língua sofre mais as mutações do tempo que o nível sintático. O acervo lexical disponível dos Xukuru no livro Mãe Natureza organizado por Almeida (1994) é um importante resquício do que possivelmente foi a língua homônima dos Xukuru.

A questão da língua é delicada e um ponto de constrangimento para muitos Xukuru, pois muitos consideram o Sucuru (Xukuru) como língua morta. A língua não se presta mais à interação entre os falantes, mas existe em forma de registro e isso deve ser considerado. Lapenda (1962) fez amplo registro do que chamou dialeto Xukuru, coletando os vocábulos dos mais velhos, muitos dos quais não estão catalogados no livro Mãe Natureza (ALMEIDA, 2000). Os resultados de nossas análises (2018) sinalizam para variações de uso possivelmente condicionadas diastraticamente, conforme a classificação das variáveis dependentes (estrutural e social). Apontam ainda para a ocorrência de redução vocabular. Foi demonstrado que a polissemia é uma realidade dos registros dos processos fonológicos. Inferimos que tal diversidade linguística pode estar relacionada à lógica do pensar cultural pelo qual um povo sente a necessidade de representação por nova lexia. Podemos exemplificar essa prática linguística, por conceito, para especificar a localização, por exemplo, se o falante quiser exemplificar que o pé é de alguém, vai usar uma palavra, mas se quer enfatizar a posse (pé dele mesmo) a palavra pé já vai ser representada de outra forma, usando nova lexia.

Outro exemplo é o verbo matar (grago) que pode ficar Kugago se se referir a matar por espancamento, ou seja, a depender da ocorrência, a forma altera.

As representações de mundo se diferenciam de acordo com as necessidades de seus falantes seja de especificar, localizar ou mesmo de referir-se a algum aspecto da realidade. Segundo Lapenda (1962), o sistema articulatório é o mesmo que o Português. Baseada nessa observação poderíamos pensar que tal fato possivelmente tenha condicionado o apagamento. Ainda assim, o que se tem são hipóteses e analogias. Vale destacar que esse estudioso afirma que os Xukuru são um povo único, distinto do Tupi, do Funi-ô e do Cariri. Segue um registro sobre como eles se sentem por falarem Português e não a língua de seus ancestrais:

Estamos certos de que o fato de falarmos Português não faz a gente deixar de ser Xukuru. Somos índios mesmo falando Português. Temos outras maneiras de afirmar a nossa identidade e esse livro é prova disso (ALMEIDA, 2000, p. 66).

Segundo esse registro, percebemos que os Xukuru não se sentem menos indígenas por não conhecerem e não interagirem na língua de seus ancestrais haja vista terem outros modos de demonstrar quem são. Entendemos de nossa convivência com eles, porém, que eles se ressentem do valor que o não indígena confere a outros povos que mantêm a língua.

Segundo Rodrigues (2005), por meio de uma língua podemos identificar sua ascendência e suas descendências. 
Vejamos o que afirma esse estudioso de línguas indígenas:

O Xukuru deveria ter sido uma língua de relação pura. A ordem das palavras podia servir para exprimir conceitos. Essa relação era regressiva, como no Tupi e no Iatê, e diferia da do Cariri em que é progressista (...) o remanescente linguístico Xukuru são palavras conceituais, sem determinação ou categoria. São nomes (...) ou verbos são de forma nominal (LAPENDA, 1962, p. 17).

Toda a dificuldade que temos de recuperar os registros da língua pré-histórica é que ela não deixou registros como, por exemplo, o Latim. Assim, tudo o que se tem são probabilidades e hipóteses.

Não há um consenso na literatura sobre a morte de uma língua, há os que consideram que uma língua é morta quando não há mais registro. Conforme Seki (1994), Não basta está cristalizada no tempo pretérito e em desuso, mas se há um código em registro, não podemos afirmar que está morta. Já os Sociolinguistas, da perspectiva variacionista laboviana ([1972], 2008), afirmam que, se não há interação entre falantes, a língua está morta.

Podemos considerar, no entanto, a possibilidade de revitalização de uma língua se há registros de regras de funcionamento. Tudo é relativo a depender da postura do falante quanto à extinção ou vitalidade. Sabemos que a língua sofre variação e mudança no tempo e no espaço, resta saber até que ponto as transformações sofridas são justificativas para que seja considerada outra língua. Afinal não há limite de espaço e tempo para que se possa precisar os diferentes estados de uma língua.

São várias as terminologias para denominar uma língua que deixa de ser válida. Há quem chame suicídio linguístico, quando se atesta o desinteresse dos falantes quanto à interação na língua materna, o que não se enquadra os Xukuru, pois eles demonstram interesse em conhecer a língua de seus ancestrais, como comprovado na pesquisa empírica da tese ${ }^{12}$, uma vez que constatamos grande interesse da parte deles, de revitalização da língua.

Para a construção da hermenêutica do ser, entendemos como basilar a simbologia. Dentro do valor semântico que fundamenta as instituições sociais, a língua se institui como elemento de destaque para, de forma mais objetiva, fortalecer a identidade de um povo. É possível que esse entendimento justifique a busca pela língua ancestral, pois, apesar de a língua não ser uma condição sine qua non para a construção da identidade, em relação às instituições veiculadas à perpetuação dos valores simbólicos de sua materialidade financeira com recursos, envolve poder e favorece o fortalecimento da identidade étnica indígena.

É preciso entender o percurso do ser Xukuru, esse ser étnico que busca o fortalecimento de sua identidade étnica. Esse fortalecimento se dá à medida que

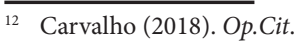


reconhecemos suas tradições; consideramos sua autoidentificação e respeitamos suas singularidades e idiossincrasias como genuína expressão de seu ser, como finalizamos a intertextualidade bíblica na Seção 2 .

\section{Considerações Finais}

Este artigo apresentou um breve repasso do papel da língua no fortalecimento da etnicidade dos grupos indígenas com foco no Xukuru da Serra de Ororumbá-PE, com base na pesquisa realizada para a Tese de Doutorado, em 2018. Nosso objetivo foi ratificar os resultados do estudo com o fim precípuo de fortalecer a etnicidade dos Xukuru.

As reflexões suscitadas ao longo do artigo levaram a algumas considerações a serem pontuadas a seguir.

Uma das conclusões a que chegamos foi que o processo de deslocamento e perda da língua se apresenta desconfortante para os grupos indígenas do Nordeste, à exceção dos Fulni-ô, possivelmente por ser, a língua, considerada o principal elemento de identificação cultural, por isso vivenciam um processo de fortalecimento de sua identidade ética, com a busca pela revitalização da língua ancestral. Foi esclarecido, no entanto que, embora seja importante, a língua não é o único elemento de identificação cultural. Os objetos simbólicos, as crenças e seu ritual sagrado são fortes indícios de identificação.

Outra conclusão quanto à justificativa do processo de apagamento linguístico, foi que a imposição do uso da Língua Portuguesa possivelmente tenha sido a maior motivação, uma vez que eram obrigados a se comunicar somente com a língua do dominador, deixando em desuso a sua língua materna. Essa obrigatoriedade se apresentou como proposta das políticas homogeneizadoras, conforme apresentado na intertextualidade bíblica.

Levou-se à reflexão também a questão que relaciona a língua ao poder, pois como ficou esclarecido, o domínio da língua e suas regras são mais usuais da classe dominante pela facilidade de acesso aos instrumentos normativos, ofertados pelo capital intelectual, e adquiridos mais facilmente pelos detentores do capital econômico, enquanto que as demais classes, na tentativa de ascender ao status da camada prestigiada da sociedade, são sempre pretendentes e, por isso, estão sempre a cometer desvios e, com muito esforço adquirir o capital cultural.

Concluímos também que as trocas linguísticas interétnicas deixaram marcas de dominação pela distinção e correção, em que a necessidade de aprofundar o conhecimento na língua dominante se faz presente na realidade social, mas naturalmente essa pretensão sempre vai ser marcada por variações de uso como é o caso do português falado pelos Xukuru em completo desvio das prescrições normativas da Língua Portuguesa.

Por fim, compreendemos que o Xukuru em sua busca pela língua ancestral, cometem desvios normativos possivelmente com pretensão de melhor se situar socialmente para melhor seguir sua trajetória em busca da verdade de seu ser, como forma de fortalecer sua etnicidade no confronto diário com o não indígena no uso da Língua Portuguesa. 


\section{Referências}

ALMEIDA, Eliene Amorim de. (Org). Xukuru - Filhos da mãe natureza: uma história de resistência e luta. Olinda: Centro de Cultura Luiz Freire, 2000.

ALMEIDA, Maria Regina Celestino de. Os índios na História do Brasil. Rio de Janeiro: FGV, 2010.

ARRUTI, José Maurício Adoniran. Morte e vida do Nordeste indígena: a emergência étnica como fenômeno histórico regional. Estudos Históricos, Rio de Janeiro, v.8, n. 15, p.57-94, 1995.

A produção da alteridade: o Toré e as conversões missionárias e indígenas in: MONTERO, Paula. Deus na aldeia missionários índios e mediação cultural, São Paulo: Globo S.A., 2006.

BAUMAN, Zygmund. Identidade. Modernidade Líquida. Trad. Plínio Dentzien. Rio de Janeiro: Zahar, 2001.

Identidade. Enrevista a Benedecto Vecchi. Trad. Carlos Alberto Medeiros. Rio de Janeiro: Zahar, 2005.

BOURDIEU, Pierre. Structuralism and Theory of Sociological Knowledge. Social Research, 35: 4 p. 681-706, 1968. Disponível em: https://www.researchgate.net/publication/281504461_'Structuralism_and_Theory_of_Sociological_Knowledge. Acesso em: 12 jul. 2019.

A economia das trocas linguísticas: o que falar quer dizer. São Paulo: Perspectiva, 2007.

A distinção: crítica social do julgamento, Porto Alegre; Zouk, 2007.

. Esboço de uma teoria da prática. In: ORTIZ, Renato (Org). A sociologia de Pierre Bourdieu. São Paulo: Ática, 1994, p. 4686. Coleção Grandes Cientistas Sociais: 39.

CARVALHO, Solange Carlos de. Convergência e divergência na acomodação dialetal: uma questão de identidade: In: CONGRESSO NACIONAL DE LÍNGUÍSTICA E FILOLOGIA. 18. 2014. Rio de Janeiro. Anais...Rio de Janeiro: Cadernos do CNLF, vol. XVIII, N. 12 - Sociolinguística, Dialetologia, 2014b p. 40-75. Disponível em: hattp:// www.filologia.org.br/xviii_cnlf/cnlf/12/004.pdf.

. A língua, o fortalecimento da identidade étnica dos Xukru da Serra do Ororubá em busca do sentido do Ser. Tese (Doutorado), Universidade Federal de Pernambuco (UFPE), 2018.

CRISTAL, David. (1987). The Cambridige Encyclopedia of Language. United States of America: Cambridge University Press, 1994. 
CUNHA, Manuela Carneiro. História dos Índios no Brasil. São Paulo: Companhia das Letras, 1992.

GILES H.; COUPLAND N. Language: contexts and consequences. Pacific Grove (Ca): Brooks, Cole, 1991.

HALL, Stuart. Identidade cultural na pós-modernidade. Rio de Janeiro: DP\&A, 2002. HEIDEGGER, Martin [1967]. Carta sobre o humanismo. Tradução Rubens Eduardo Frias. Rio de Janeiro: Tempo Brasileiro, 2005.

HEIDEGGER, Martin. Ontologia. Hermenêutica da facticidade. 2.ed. Tradução Renato Kirchner. Petrópolis: Vozes, 2013.

Ser e Tempo. 10.ed.. Tradução Marcia Sá Cavalcante Schuback. São Paulo: Editora Vozes, 2015a.

A caminho da linguagem. 7.ed. Tradução Enio Paulo Giachini, Petrópolis: Vozes 2015b.

. Sobre a essência da linguagem. Tradução Enio Paulo Giachini. Petrópolis: Vozes, 2015c.

HOFFNAGEL, Judith Chambliss. Linguagem e poder: políticas linguísticas no Brasil. In: BARRIO, Angel B. Espina (ED). Poder, Política y Cultura: antropologia em Castilla y León e Iberoamerica VII. Recife: Massangana/Fundaj, 2005.

IBGE. 2010. Indígenas. Estudos especiais: o Brasil indígena. Disponível em: https://indigenas.ibge.gov.br/estudos-especiais-3/o-brasil-indigena/lingua-falada. Acesso em: 3 jul. 2018.

LABOV, William. [1992] Padrões Sociolinguístico. Tradução Marcos Bagno e Maria Marta Pereira Sherre São Paulo, Parábola Editorial, 2008.

LAPENDA, Geraldo Calábria. O dialecto Xucuru. Doxa (Revista Oficial do Departamento de Cultura do Diretório Acadêmico da Faculdade de Filosofia de Pernambuco da Universidade do Recife), ano X, n. 10, p. 11- 23. 1962.

LEITE, Yonne. Línguas indígenas brasileiras e a esperança de um futuro. Rio de Janeiro: UFRJ, Museu nacional e GFU, 2009.

LUDEMIR, Chico. Povo Xukuru: pé no chão e raízes profundas. In: Revista Continente. Edição Extra, 2019. Disponível em: https://www.revistacontinente.com.br/secoes/extra/povo-xukuru--pe-no-chao-e-raizes-profundas. Acesso em: 9 jun. 2019.

MALINOVISKY, Bronislaw. O Argonauta do Pacífico Ocidental. São Paulo: Abril Cultural, 1978. 
OLIVEIRA, João Pacheco de (Org.). Uma etiologia dos “índios misturados”? Situação colonial (territorialização e fluxos culturais. Mana: estudos de antropologia social, Rio de Janeiro: Universidade Federal do Rio de Janeiro - UFRJ, Programa de Pós-Graduação em Antropologia Social (PPGAS-Museu Nacional), v. 4, n. 1, p. 47-77, abr 1998.

(Coord.). Atlas das Terras Indígenas do Nordeste. Rio de Janeiro: PETI/ Museu Nacional, 1993.

A viagem da volta: etnicidade, política e reelaboração cultural no nordeste indígena. Rio de Janeiro: Contra Capa, 1999.

(Org). A presença indígena no Nordeste: processos de territorialização, modos de reconhecimento e regimes de memória. Rio de Janeiro: Contra Capa, 2011.

RODRIGUES, Aryon Dall'gna. Os índios do Nordeste: levantamento sobre os remanescentes tribais do Nordeste brasileiro. Tradução Yonne Leite. Cuiabá-MT: Sociedade Internacional de Linguística, 1976.

. Relações internas da família Tupi-Guarani. Revista de Antropologia, v.3, n. 2, 2011. Disponível em: <file://C:/Users/solange.carvalho/Downloads/8868-28297-1PB.pdf>. Acesso em: 15 jun 2018. 1986.

. Línguas Brasileiras: para o conhecimento das línguas indígenas. São Paulo: Loyola, . Sobre as línguas indígenas e sua pesquisa no Brasil. Ciência e Cultura, v. 57, n. 2, p. 35-38, 2005.

. Línguas indígenas brasileiras ameaçadas de extinção. Laboratório de Línguas Indígenas, Universidade de Brasília.[s.d] Disponível em:

$<$ http://projetos.unioeste.br/projetos/cidadania/images/stories/Fevereiro/Linguas_ indigenas_brasileiras_ameaadas_de_extino.pdf >

. Línguas indígenas: 500 anos de descobertas e perdas. D.E.L.T.A. São Paulo, v.9, n.1, p. 83-1-3. 1993.

A originalidade das línguas brasileiras. Revista Brasileira de Linguística e Antropologia. v. 8, n. 2, dez. 2016.

Disponívelem:<http://periodicos.unb.br/index.php/ling/article/viewFile/27188/19200>

SEKI, lUCY. Problemas no estudo em um alíngua em extinção. Boletim. Abralim, 1994. In. Simpósio/Unicap. Disponível em: http://www.etnolinguistica.org;biblio:contato. Acesso em> 24 abril 2018.

SILVA, Hosana dos Santos. Breve introdução à história das línguas. São Paulo: UNIFEST, 2015. 
SILVA, Hely Edson. O lugar do índio: conflitos, esbulhos de terras e resistência indígena no século XIX: o caso de Escada-PE (1860-1880). Dissertação (Mestrado em História) - Universidade Federal de Pernambuco, Recife, 1995.

SILVA, Hely Edson. Os caboclos que são índios. Belém do São Francisco: Cevasf, 2004. História, memórias e identidades entre os Xukuru de Ororubá. Tellus, ano 7.n.12, p. 89-102, 2007.

; SILVA, Maria da Penha. A temática indígena na sala de aula: reflexões para o ensino a partir da Lei 11.645, Recife Editora Universitária/UFPE, 2013.

Xukuru: Memórias e história dos índios da Serra de Ororubá (Pesqueira/PE), 1950-1988. Recife: UFPE], 2014.

SILVA, José Bozacchiello da. et al. Litoral e Sertão, natureza e sociedade no Nordeste Brasileiro. Fortaleza: Expressão Gráfica, 2006.

SILVA, Braulio Henrique Avelino; SANTOS, Kleber Emmanuel Oliveira. Os desafios da educação nas escolas indígenas do povo Xukuru do Ororubá: uma reflexão à luz dos direitos humanos. II Congresso Internacional De Educação Inclusiva II CINTEDI. Anais [...]Campina Grande, PB, 2016. Disponível em: https://editorarealize.com.br/revistas/ cintedi/trabalhos/TRABALHO_EV060_MD1_SA12_ID3784_13102016163754.pdf. Acesso em: 26 jul 2018.

SILVA, Kalina Vanderlei. Nas solidões vastas e assustadoras. A conquista do sertão de Pernambuco pelas vilas açucareiras nos séculos XVII e XVIII. Recife: Cepe, 2010.

VANDENBERGHE, Fredéric. O real é relacional: uma análise epistemológica do estruturalismo gerativo de Pierre Bourdieu, 2002. VANDENBERGHE, Frédéric. VANDENBERGHE, F. Teoria Social Realista. Belo Horizonte: UFMG \& Rio de Janeiro: IUPERJ, 2010.

WACQUANT, Loïc. Poder simbólico e fabricação de grupo. In: Bourdieu e a questão de classes. Novos Estudos-Cebrap, São Paulo, jun, 2013. p. 87-103.

Disponível em: <http://www.scielo.br/scielo.php?script=sci_arttext\&pid=S0101$33002013000200007 \& \operatorname{lng}=\mathrm{en} \& \mathrm{nrm}=\mathrm{iso} \& \operatorname{lng}=\mathrm{pt}>$. Acesso em: 15 maio 2016.

Bourdieu e a questão das classes. Novos estudos - Cebrap, 96, São Paulo July, 2013. Disponível em: <http://www.scielo.br/scielo.php?pid=S0101=33002013000200007-\&scriptsci_arttext.>. Acesso em: out 2015. 